\title{
Overview Penyediaan Kapasitas Pembangkit Listrik Tenaga Air Berdasarkan Rencana Umum Energi Nasional (RUEN)
}

\author{
Hendra Ardi Kurniawan, Jaka Windarta \\ Magister Energi, Sekolah Pascasarjana, Universitas Diponegoro;

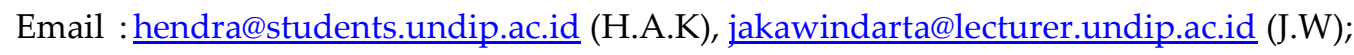

\begin{abstract}
Abstrak : Seperti terlampir pada Rencana Umum Energi Nasional (RUEN), peran EBT ditargetkan minimal sebesar $23 \%$ dari total kebutuhan energi pada Tahun 2025. Secara khusus, penelitian ini membahas mengenai pemantauan penyediaan kapasitas pembangkit Pembangkit Listrik Tenaga Air (PLTA) guna untuk mendukung bauran energi sebesar 23\%. Overview yang dilakukan melibatkan dua sumber data sebagai data sekunder yang berasal dari data pemodelan RUEN dan BPS. Pengumpulan data dilakukan yang kemudian dilanjutkan dengan perbandingan antara ketersediaan kapasitas aktual dengan pemodelan RUEN. Secara keseluruhan, pencapaian aktual penyediaan pembangkit PLTA memiliki gap sebesar 3\% dari RUEN dimana Provinsi Kalimantan Barat menunjukkan penyediaan kapasitas pembangkit tertinggi berdasaran RUEN sebesar 234,27 MW dari perencanaan 2,2 MW sedangkan Provinsi Aceh menunjukkan provinsi yang memiliki progres paling rendah jika dibandingkan dengan provinsi lain yakni sebesar 2,64 MW dari perencanaan 128,4 MW. Studi lanjutan perlu dilakukan sebagai justifikasi dari setiap kemajuan dan/atau keterlambatan penyediaan yang disetiap wilayah sehingga dapat digunakan sebagai lesson learned untuk provinsi lain.
\end{abstract}

Kata Kunci : RUEN, PLTA, Kapasitas Pembangkitan

\section{Pendahuluan}

Rencana Umum Energi Nasional (RUEN) merupakan hasil dari amat Undang-Undang (UU) Nomor 30 Tahun 2017 yang meliputi lingkup energi. RUEN berisikan kebijakan Pemerintah Pusat yang mengatur rencana pengelolaan energi tingkat nasional yang merupakan pejabaran dan perencanaan pelaksanaan dari Kebijakan Energi Nasional (KEN) yang berisikan pemodelan kebutuhan-pasokan hingga 2025 serta strategi untuk mencapai sasaran tersebut. RUEN bertindak merupakan pedoman dalam pengelolaan energi nasional sebagai usaha untuk mewujudkan kemandirian energi dan ketahanan energi nasional. RUEN juga digunakan sebagai acuan dalam penyusunan Rencana Umum Energi Daerah (RUED). Paradigma kebijakan energi tidak lagi menjadikan sumber daya energi menjadi komoditas ekspor namun bertindak sebagai modal pembangunan nasional. Untuk mendukung terlaksananya tujuan tersebut, diperlukan berbagai terobosan yang telah terlampir sesuai dalam RUEN yang terdiri dari 5 Bab dan ditunjukkan pada Tabel 1 (Widyaningsih, 2017). 
Tabel 1.

Sistematika RUEN (Widyaningsih, 2017)

\begin{tabular}{|c|c|c|}
\hline BAB & Keterangan & Substansi \\
\hline BAB I & Pendahuluan & Latar Belakang \\
\hline BAB II & $\begin{array}{l}\text { Kondisi Energi Nasional Saat } \\
\text { ini dan Ekspektasi Masa } \\
\text { Mendatang }\end{array}$ & $\begin{array}{l}\text { - Isu dan permasalahan umum terkait energi. } \\
\text { - Kondisi ekonomi dan energi saat ini dan ke } \\
\text { depan (Indikator sosio-ekonomi, indicator energi, } \\
\text { dan indicator lingkungan). } \\
\text { - Hasil pemodelan kebutuhan dan pasokan energi, } \\
\text { serta dampak emisi GRK tahun 2015-2050. }\end{array}$ \\
\hline BAB III & $\begin{array}{l}\text { Visi, Misi, Tujuan dan Sasaran } \\
\text { Energi Nasional }\end{array}$ & $\begin{array}{l}\text { Menjabarkan Visi, Misi, Tujuan, dan Sasaran yang } \\
\text { terdapat dalam KEN }\end{array}$ \\
\hline BAB IV & $\begin{array}{l}\text { Kebijakan dan Strategi } \\
\text { Pengelolaan Energi Nasional }\end{array}$ & $\begin{array}{l}\text { - Kebijakan strategi, program, dan kegiatan } \\
\text { unggulan untuk mencapai sasaran KEN } \\
\text { (ringkasan dari Lampiran Matriks Program). } \\
\text { - Rencana indikatif pengembangan energi per } \\
\text { provinsi/wilayah. }\end{array}$ \\
\hline BAB V & Penutup & Kesimpulan \\
\hline LAMPIRAN & Matriks Program & $\begin{array}{l}\text { - Rincian detail kebijakan, strategi, program dan } \\
\text { kegiatan yang akan dilakukan berdasarkan PP } \\
\text { No. 79/2014 tetang KEN. } \\
\text { - Mencantumkan Kementerian Negara/Lembaga } \\
\text { yang bertanggung jawab dan instrument } \\
\text { kebijakan yang diperlukan. }\end{array}$ \\
\hline
\end{tabular}

Pada Bab II RUEN dijelaskan mengenai kondisi energi nasional saat ini dan ekspektasi mendatang, secara garis besar kondisi energi nasional memiliki beberapa isu dan permasalahan energi sebagai berikut:

1) Sumber daya energi masih diperlakukan sebagai komoditas sebagai sumber devisa belum sebagai modal pembangunan.

2) Penurunan produksi dan gejolak harga minyak.

3) Akses dan infrastruktur yang terbatas.

4) Ketergantungan akan impor bahan bakar (BBM dan LPG).

5) Harga EBT yang belum kompetitif.

6) Pemanfaatan EBT yang rendah.

7) Pemanfaatan energi yang belum efisien.

8) Penelitian, pengembangan, dan penguasaan ilmu pengetahuan dan teknologi yang terbatas.

9) Kondisi geopolitik.

10) Ketidaktersediaan cadangan penyangga energi.

Masih pada Bab yang sama juga dijelaskan terkait kondisi energi nasional saat ini dimana asumsi dasar (key assumption) ditetapkan sebagai dasar perencanaan energi. Sehingga dengan adanya asumsi dasar tersebut dapat tercapai satu diantara beberapa sasaran yakni tercapainya bauran energi primer yang optimal. Dalam sasaran tersebut, proporsi EBT pada bauran energi primer adalah paling sedikit 
sebesar 23\% pada tahun 2025 dan 31\% pada tahun 2050. Detail bauran energi terlampir pada Tabel 2. Dengan adanya target tersebut diharapkan dapat menggeser dominasi energi bahan bakar fosil dimana dapat dilakukan dengan optimalisasi penggunaan energi baru terbarukan (Windarti, 2014).

\section{Tabel 2.}

Distribusi Target Bauran Energi Primer 2025 dan 2050 (Widyaningsih, 2017)

\begin{tabular}{llcc}
\hline \multirow{2}{*}{ No. } & \multirow{2}{*}{ Sasaran KEN } & \multicolumn{2}{c}{ Target bauran energi (\%) } \\
\cline { 2 - 4 } & & 2025 & 2050 \\
\hline 1 & EBT & $>23 \%$ & $>31 \%$ \\
2 & Minyak Bumi & $<25 \%$ & $<20 \%$ \\
3 & Batu Bara & $>30 \%$ & $>25 \%$ \\
4 & Gas Bumi & $>22 \%$ & $>24 \%$ \\
\hline
\end{tabular}

\section{Potensi Sumber Daya Energi Primer Air}

Pembangkitan energi yang menggunakan air merupakan pembangkitan energi yang memanfaatkan adanya energi potensial dan kinetik dari aliran air. Kondisi aliran air yang dapat dimanfaatkan sebagai sumber energi adalah memiliki kapasitas aliran dengan ketinggian tertentu (Fachri et al., 2019). Pemanfaatan dari PLTA dapat memberikan nilai positif yang berantai pada lintas sektor yaitu pemanfaatan energi air, pelestarian daerah aliran sungai, dan menjaga keberlangsungan pasokan air baik bagi PLTA maupun irigasi (Astro et al., 2020).

Besaran potensi pembangkitan listrik tenaga air adalah sebesar 75.000 MW dimana baru 9\% dari potensi tersebut yang telah dimanfaatkan baik dalam pembangkit skala kecil maupun besar (Erinofiardi et al., 2017). Sebagai pembanding, potensi tenaga air di negara bekas Uni Soviet yang mencapai 98.000 MW dengan jumlah bendungan sekitar 500 buah dengan keseluruhan kapasitas terpasang PLTA 66.000 MW atau sekitar 67 persen dari potensi yang tersedia (Ratnata et al., 2013). Berdasarkan data potensi energi terbarukan Indonesia tahun 2015, potensi energi air menduduki peringkat kedua setelah surya dengan besar potensi 75.000 MW. Secara detail potensi energi terbarukan Indonesia tahun 2015 dijelaskan pada Tabel 3.

\section{Tabel 3.}

Potensi Energi Terbarukan Indonesia (Widyaningsih, 2017)

\begin{tabular}{clcc}
\hline No. & \multicolumn{1}{c}{ Jenis Energi } & Potensi & Used \\
\hline 1 & Panas Bumi & $29.544 \mathrm{MW}$ & $4,9 \%$ \\
2 & Air & $75.091 \mathrm{MW}$ & $6,4 \%$ \\
3 & Mini \& Mikro Hidro & $19.385 \mathrm{MW}$ & $1,0 \%$ \\
4 & Bioenergi & $32.654 \mathrm{MW}$ & $5,1 \%$ \\
5 & Surya & $207.898 \mathrm{MW}$ & $0,04 \%$ \\
6 & Angin & $60.647 \mathrm{MW}$ & $0,01 \%$ \\
7 & Laut & $17.989 \mathrm{MW}$ & $0,002 \%$ \\
\hline \multicolumn{2}{c}{ Total } & $443.208 \mathrm{MW}$ & $1,9 \%$ \\
\hline
\end{tabular}

Besaran potensi energi air sebesar 75.000 MW terdistribusi pada wilayah di Indonesia dengan potensi terbesar berada di Provinsi Papua sebesar 22.371 MW. Secara detail potensi tenaga air per wilayah dijelaskan pada Tabel 4. 
Tabel 4.

Distribusi Potensi Tenaga Air Per Wilayah

\begin{tabular}{clc}
\hline No. & \multicolumn{1}{c}{ Wilayah/Provinsi } & Potensi (MW) \\
\hline 1 & Papua & 22.371 \\
2 & Kalsel, Kalteng, Kaltim & 16.844 \\
3 & Sulses, Sultra & 6.340 \\
4 & Aceh & 5.062 \\
5 & Kalimantan Barat & 4.737 \\
6 & Sulut, Sulteng & 3.967 \\
7 & Sumatera Utara & 3.808 \\
8 & Sumatera Barat, Riau & 3.607 \\
9 & Sumsel, Bengkulu, Jambi, Lampung & 3.102 \\
10 & Jawa Barat & 2.861 \\
11 & Jawa Tengah & 813 \\
12 & Bali, NTB, NTT & 624 \\
13 & Jawa Timur & 525 \\
14 & Maluku & 430 \\
\hline & \multicolumn{2}{c}{ TOTAL } \\
\hline
\end{tabular}

Berdasarkan data pada tabel 4, dapat terlihat bahwa potensi tenaga air pada wilayah luar Jawa mendominasi potensi yang ada sehingga pembangkitan listrik diluar pulau Jawa akan didominasi oleh PLTA (Wahid, 2006).

\section{Arah dan Kebijakan Pengembangan Potensi Sumber Daya Energi Primer Air}

Pemerintah melalui RUEN yang telah disahkan telah mencanangkan perencanaan energi khususnya pada energi primer EBT. Secara garis besar, keseimbangan sisi kebutuhan dan pasokan energi pada bauran EBT tahun 2025 adalah paling sedikit sebesar 23\% dan 2050 sebesar 31\%. Secara khusus pada energi air, pengembangan tenaga air diproyeksikan mencapai 18 GW pada 2025 dan 38 GW pada 2050 atau sebesar 51\% dari 75 GW. Pada kebijakan yang ditetapkan, juga telah dimodelkan pengembangan listrik tenaga air pada tahun 2015 - 2050. Adapun detail pemodelan pengembangan PLTA ditunjukkan pada Gambar 1.

Untuk mendukung pencapaian dari target yang telah dicanangkan, pemerintah mengeluarkan beberapa kebijakan yang telah tercantum dalam RUEN. Beberapa studi telah melakukan studi terkait permasalahan pengembangan energi terbarukan, dimana satu diantara studi menyatakan bahwa kebijakan yang telah dikeluarkan oleh pemerintah masih kurang memberikan dampak, dimana kebijakan tarif listrik yang seharusnya mampu mendorong perkembangan energi terbarukan tidak menjadi prioritas (Notosudjono et al., 2016). Biaya operasi PLTA jika dibandingkan dengan pembangkit EBT lain memiliki biaya operasi dibawah BPP Nasional, sedangkan PLTP, dan PLTS ratarata biaya operasinya berada di atas BPP Nasional. Sesuai dengan Permen ESDM No. 50 Tahun 2017 dimana pemerintah menetapkan harga patokan tertinggi sebesar 85\% (PLTS, PLTB, PLTBM) dan $100 \%$ (PLTA, PLTS, PLTP) dari BPP Nasional. Adanya kebijakan tersebut memungkinkan PLN selaku pembeli dari listrik EBT dapat melakukan penghematan sebesar 6,1 s/d 8,7 trilyun rupiah (Dalimi, 2018). 
Vol. 2, No. 3, pp $133-143$

doi: $10.14710 /$ jebt.2021.10045

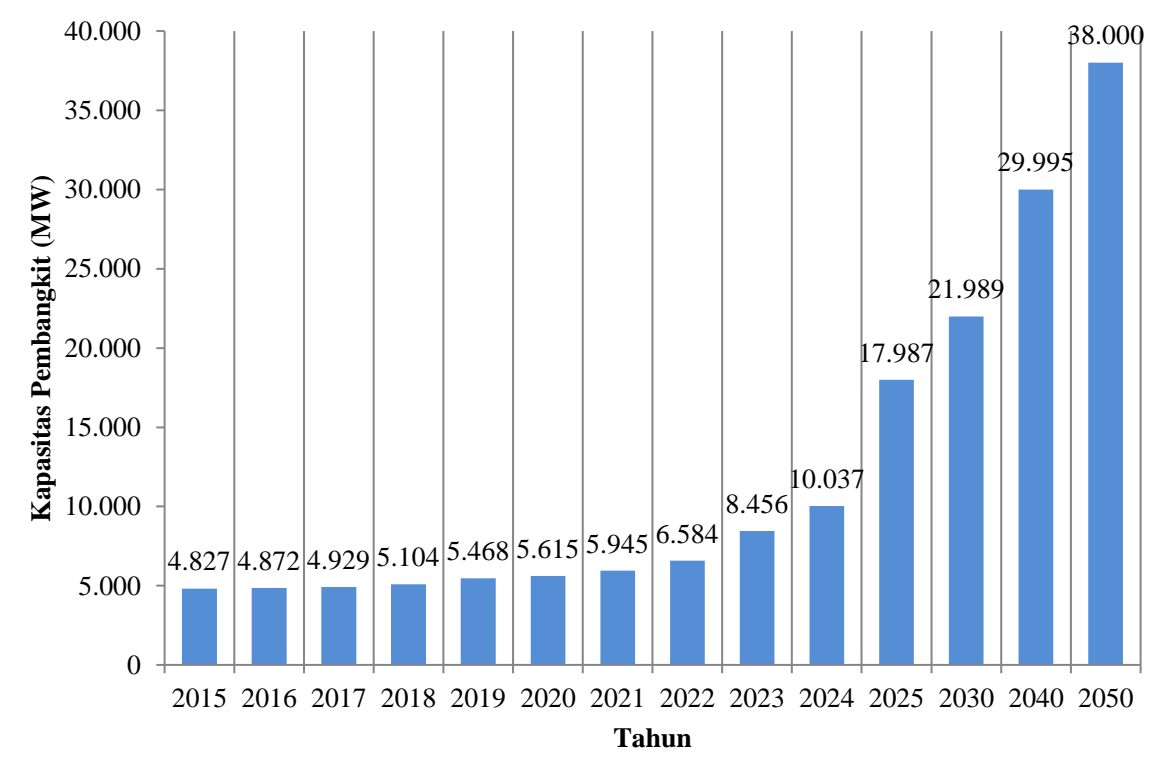

Gambar 1. Pemodelan Pengembangan PLTA berdasarkan RUEN 2015-2050

\section{Overview Pengembangan Potensi Sumber Daya Energi Primer Air 2015 - 2019}

Overview terhadap penyediaan kapasitas Pembangkit Listrik Tenaga Air berdasarkan Rencana Umum Energi Nasional (RUEN) perlu untuk dilakukan guna memastikan pelaksanaan dari rencana yang telah direncanakan dapat terlaksana sesuai dengan pemodelan. Metodologi yang dilakukan adalah dengan melalukan perbandingan data antara pemodelan pengembangan PLTA berdasarkan RUEN dengan aktual kapasitas terpasang Pembangkit Listrik Tenaga Air (PLTA) menurut provinsi. Gambar 2 menunjukkan diagram alir overview yang dilakukan.

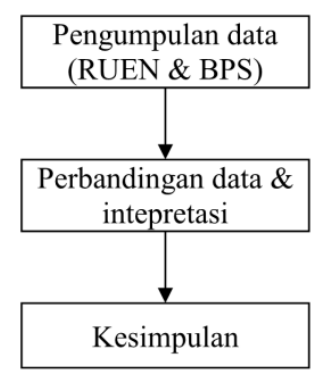

Gambar 2. Diagram Alir Overview Pengembangan PLTA 2015-2050

Dalam overview yang dilakukan, pembahasan dibatasi hanya pada periode waktu yaitu 2015 2025. Hal ini didasari oleh ketersediaan data pemodelan RUEN detail hanya tersedia sampai dengan tahun 2025, selain itu data pembanding yang dapat dikumpulkan hanya hingga tahun 2019. Pada Tabel 5 dan Gambar 3 dijelaskan hasil plot antara pemodelan RUEN dan aktual kapasitas terpasang pembangkit. Berdasarkan gambar tersebut, kapasitas terpasang pembangkit sampai dengan tahun 2019 cenderung sesuai dengan pemodelan yang telah direncanakan, dimana rata-rata besaran gap antara RUEN dan aktual sebesar 3\% untuk tahun 2015-2019. 
Tabel 5.

Perbandingan Kapasitas PLTA Terpasang dan RUEN Tahun 2015 - 2019

\begin{tabular}{|c|c|c|c|c|c|c|c|c|c|c|c|}
\hline \multirow{3}{*}{ No. } & \multirow{3}{*}{ Provinsi } & \multicolumn{10}{|c|}{ Kapasitas PLTA (MW) } \\
\hline & & \multicolumn{2}{|c|}{2015} & \multicolumn{2}{|c|}{2016} & \multicolumn{2}{|c|}{2017} & \multicolumn{2}{|c|}{2018} & \multicolumn{2}{|c|}{2019} \\
\hline & & Aktual & RUEN & Aktual & RUEN & Aktual & RUEN & Aktual & RUEN & Aktual & RUEN \\
\hline 1 & Jawa Barat & 947,00 & $1.991,9$ & 947,36 & $1.991,9$ & $1.999,26$ & $2.038,9$ & $1.985,36$ & $2.038,9$ & $1.983,86$ & $2.148,9$ \\
\hline 2 & Sulawesi Selatan & 155,42 & 521,6 & 161,60 & 521,6 & 162,90 & 521,6 & 585,27 & 521,6 & 586,07 & 521,6 \\
\hline 3 & Sumatera Utara & $1.026,00$ & 922,5 & $1.026,00$ & 967,5 & $1.078,50$ & 967,5 & $1.036,50$ & 967,5 & $1.036,30$ & $1.204,0$ \\
\hline 4 & Papua & 4,46 & 3,9 & 24,46 & 3,9 & 25,13 & 3,9 & 24,60 & 3,9 & 25,13 & 3,9 \\
\hline 5 & Aceh & 2,62 & 2,4 & 2,62 & 2,4 & 2,42 & 12,4 & 2,42 & 110,4 & 2,64 & 128,4 \\
\hline 6 & $\begin{array}{c}\text { Nusa Tenggara } \\
\text { Timur }\end{array}$ & 4,88 & - & 5,28 & - & 5,18 & - & 5,28 & - & 5,28 & - \\
\hline 7 & Sulawesi Barat & 6,18 & - & - & - & - & - & - & - & - & - \\
\hline 8 & Jawa Tengah & 310,07 & 306,8 & 310,48 & 306,8 & 310,97 & 306,8 & 310,00 & 306,8 & 322,14 & 306,8 \\
\hline 9 & $\begin{array}{l}\text { Kalimantan } \\
\text { Timur }\end{array}$ & - & - & - & - & - & - & - & - & - & - \\
\hline 10 & Jawa Timur & $1.301,22$ & 293,2 & $1.302,13$ & 293,2 & 309,85 & 293,2 & 293,35 & 293,2 & 293,35 & 293,2 \\
\hline 11 & Sulawesi Tengah & 234,35 & 195,0 & 235,95 & 195,0 & 235,95 & 195,0 & 235,95 & 195,0 & 235,95 & 195,0 \\
\hline 12 & Sumatera Barat & 0,66 & 254,2 & 0,66 & 254,2 & 0,66 & 254,2 & 0,66 & 254,2 & 243,00 & 254,2 \\
\hline 13 & Jambi & - & - & - & - & - & - & - & - & - & - \\
\hline 14 & Papua Barat & 2,00 & 2,0 & 5,13 & 2,0 & 4,46 & 2,0 & 5,13 & 2,0 & 4,66 & 2,0 \\
\hline 15 & Bengkulu & 1,60 & 248,0 & 1,60 & 248,0 & 1,60 & 248,0 & 13,60 & 269,0 & 13,60 & 269,0 \\
\hline 16 & Kalimantan Barat & 2,03 & 2,2 & 2,03 & 2,2 & 2,02 & 2,2 & 234,26 & 2,2 & 234,27 & 2,2 \\
\hline 17 & Kalimantan Utara & - & - & - & - & - & - & - & - & - & - \\
\hline 18 & $\begin{array}{l}\text { Sulawesi } \\
\text { Tenggara }\end{array}$ & 4,15 & 1,6 & 4,15 & 1,6 & 4,10 & 1,6 & 0,50 & 1,6 & 0,50 & 1,6 \\
\hline 19 & $\begin{array}{l}\text { Kalimantan } \\
\text { Selatan }\end{array}$ & 30,00 & 30,0 & 30,00 & 30,0 & 30,00 & 30,0 & 30,00 & 30,0 & 30,00 & 30,0 \\
\hline 20 & Sulawesi Utara & 56,38 & 51,4 & 56,38 & 51,4 & 56,38 & 51,4 & 5,25 & 51,4 & 5,25 & 51,4 \\
\hline 21 & Lampung & - & - & - & - & - & - & 56,00 & 56,0 & 56,00 & 56,0 \\
\hline 22 & Riau & - & - & - & - & - & - & - & - & - & - \\
\hline 23 & $\begin{array}{c}\text { Nusa Tenggara } \\
\text { Barat }\end{array}$ & 2,00 & - & 2,02 & - & 2,02 & - & 2,02 & - & 2,02 & - \\
\hline 24 & Maluku & - & - & - & - & - & - & - & - & - & - \\
\hline 25 & Sumatera Selatan & 620,15 & - & 620,23 & - & 620,42 & - & 608,42 & - & 608,42 & - \\
\hline 26 & D.I. Yogyakarta & 0,32 & - & 0,18 & - & - & - & - & - & - & - \\
\hline 27 & Gorontalo & 1,20 & - & 1,20 & - & 1,20 & - & 1,20 & - & 1,20 & - \\
\hline & & $4.712,69$ & $4.826,7$ & $4.739,46$ & $4.871,7$ & $4.853,02$ & $4.928,7$ & $5.435,77$ & $5.103,7$ & $5.689,64$ & $5.468,2$ \\
\hline
\end{tabular}




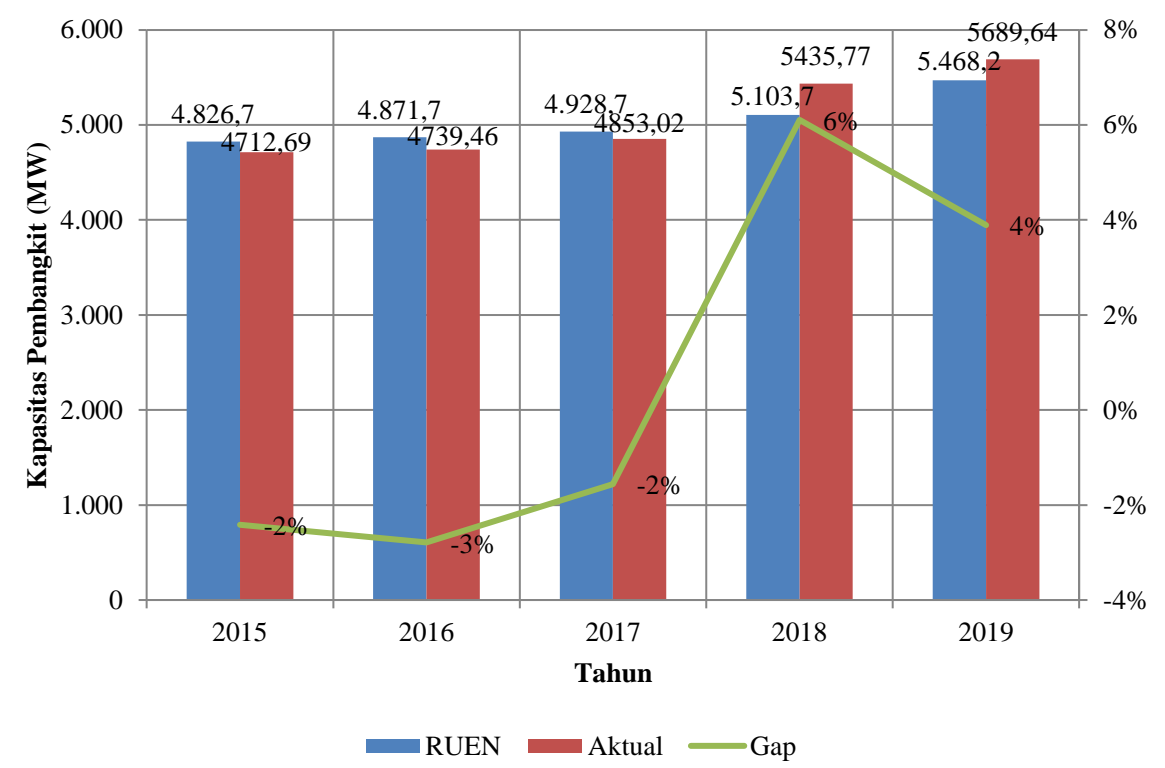

Gambar 3. Plot Kapasitas PLTA Hasil Pemodelan RUEN dan Aktual 2015-2019

Penjabaran lebih lanjut dilakukan dengan melakukan overview pada masing-masing wilayah/provinsi berdasarkan pemodelan RUEN dan aktual. Pengelompokan provinsi berdasarkan indikasi rencana penyediaan kapasitas PLTA 2015-2025 RUEN dikelompokkan menjadi 24 provinsi, tidak adanya keterangan pada 10 provinsi lainnya menyebabkan provinsi yang tidak terdapat pada daftar RUEN tidak dapat dilakukan perbandingan (Badan Pusat Statistik, 2020).

1) Provinsi Jawa Barat merupakan provinsi yang memiliki potensi energi air sebesar $2.861 \mathrm{MW}$ dengan kapasitas terpasang saat ini sebesar 1.983,86 MW atau sebesar 69,34\% dari potensi yang ada. Kapasitas terpasang pembangkit sampai dengan tahun 2019 memiliki rata-rata besaran gap antara RUEN dan aktual sebesar -23\% dimana ketertinggalan penyediaan pembangkitan terus terjadi pada tahun 2015-2019.

2) Provinsi Sulawesi Selatan merupakan provinsi yang memiliki potensi energi air sebesar 6.340 MW dimana potensi tersebut merupakan gabungan antara provinsi Sulawesi Selatan dan Sulawesi Tenggara dengan kapasitas terpasang saat ini sebesar 586,57 MW atau sebesar 9,24\% dari potensi yang ada. Kapasitas terpasang pembangkit sampai dengan tahun 2019 memiliki rata-rata besaran gap antara RUEN dan aktual sebesar -37\% dimana ketertinggalan penyediaan pembangkitan terdapat pada tahun 2015-2017, sedangkan pada tahun 2018 kapasitas pembangkitan telah mendekati rencana RUEN dimana terdapat gap sebesar $12 \%$ dan stabil hingga tahun 2019.

3) Provinsi Sumatera Utara merupakan provinsi yang memiliki potensi energi air sebesar 3.808 MW dengan kapasitas terpasang saat ini sebesar 1.036,3 MW atau sebesar 27,21\% dari potensi yang ada. Kapasitas terpasang pembangkit sampai dengan tahun 2019 memiliki rata-rata besaran gap antara RUEN dan aktual sebesar 4\% dimana ketertinggalan penyediaan pembangkitan terdapat pada tahun 2019 sebesar $-14 \%$.

4) Provinsi Papua merupakan provinsi yang memiliki potensi energi air sebesar 22.371 MW dimana potensi tersebut merupakan gabungan antara provinsi Papua dan Papua Barat dengan kapasitas terpasang saat ini sebesar 29,79 MW atau sebesar 0,112\% dari potensi yang 
ada. Kapasitas terpasang pembangkit sampai dengan tahun 2019 memiliki rata-rata besaran gap antara RUEN dan aktual sebesar 432\% dimana tidak terdapat ketertinggalan penyediaan pembangkitan selama 2015-2019.

5) Provinsi Aceh merupakan provinsi yang memiliki potensi energi air sebesar 5.062 MW dengan kapasitas terpasang saat ini sebesar 2,64 MW atau sebesar 0,052\% dari potensi yang ada. Kapasitas terpasang pembangkit sampai dengan tahun 2019 memiliki rata-rata besaran gap antara RUEN dan aktual sebesar $-52 \%$ dimana terdapat ketertinggalan penyediaan pembangkitan selama 2017-2019.

6) Provinsi Nusa Tenggara Timur merupakan provinsi yang memiliki potensi energi air sebesar $624 \mathrm{MW}$ dimana potensi tersebut merupakan gabungan antara provinsi Bali dan Nusa Tenggara Barat dengan kapasitas terpasang saat ini sebesar 5,28 MW atau sebesar 0,846\% dari potensi yang ada. Kapasitas terpasang pembangkit sampai dengan tahun 2019 selalu berada lebih besar dari RUEN.

7) Kapasitas terpasang pembangkit pada Sulawesi Barat sempat mengalami kondisi lebih dari yang rencanakan, namun pada tahun 2016-2019 kapasitas kembali menjadi 0.

8) Provinsi Jawa Tengah merupakan provinsi yang memiliki potensi energi air sebesar $813 \mathrm{MW}$ dengan kapasitas terpasang saat ini sebesar 322,14 MW atau sebesar 39,62\% dari potensi yang ada. Kapasitas terpasang pembangkit sampai dengan tahun 2019 memiliki rata-rata besaran gap antara RUEN dan aktual sebesar $2 \%$ dimana tidak terdapat ketertinggalan penyediaan pembangkitan selama 2015-2019.

9) Kapasitas PLTA di Provinsi Kalimantan Timur berdasarkan data RUEN dan aktual, kondisi pada tahun 2015-2019 menunjukkan 0 MW.

10) Provinsi Jawa Timur merupakan provinsi yang memiliki potensi energi air sebesar $525 \mathrm{MW}$ dengan kapasitas terpasang saat ini sebesar 293,35 MW atau sebesar 55,88\% dari potensi yang ada. Kapasitas terpasang pembangkit sampai dengan tahun 2019 memiliki rata-rata besaran gap antara RUEN dan aktual sebesar 139\% dimana tidak terdapat ketertinggalan penyediaan pembangkitan selama 2015-2019.

11) Provinsi Sulawesi Tengah merupakan provinsi yang memiliki potensi energi air sebesar 3.967 MW dimana potensi tersebut merupakan gabungan antara provinsi Sulawesi Tengah dan Sulawesi Utara dengan kapasitas terpasang saat ini sebesar 235,95 MW atau sebesar 5,95\% dari potensi yang ada. Kapasitas terpasang pembangkit pada Sulawesi Tengah berada diatas rencana RUEN pada tahun 2016-2019 dengan rata-rata besaran gap antara RUEN dan aktual sebesar $21 \%$.

12) Provinsi Sumatera Barat merupakan provinsi yang memiliki potensi energi air sebesar 3.607 MW dimana potensi tersebut merupakan gabungan antara provinsi Sumatera Barat dan Riau dengan kapasitas terpasang saat ini sebesar $243 \mathrm{MW}$ atau sebesar 6,74\% dari potensi yang ada. Kapasitas terpasang pembangkit sampai dengan tahun 2019 memiliki rata-rata besaran gap antara RUEN dan aktual sebesar $-81 \%$ dimana terdapat keterlambatan pada tahun 2015-2018, kemudian terdapat peningkatan pada tahun 2019.

13) Kapasitas PLTA di Provinsi Jambi berdasarkan data RUEN dan aktual, kondisi pada tahun 2015-2019 menunjukkan 0 MW.

14) Provinsi Papua Barat merupakan provinsi yang memiliki potensi energi air $22.371 \mathrm{MW}$ dimana potensi tersebut merupakan gabungan antara provinsi Papua dan Papua Barat 
dengan kapasitas terpasang saat ini sebesar 4,66 MW atau sebesar 0,021\% dari potensi yang ada. Kapasitas terpasang pembangkit sampai dengan tahun 2019 memiliki rata-rata besaran gap antara RUEN dan aktual sebesar 114\% dimana tidak terdapat ketertinggalan penyediaan pembangkitan selama 2016-2019.

15) Provinsi Bengkulu merupakan provinsi yang memiliki potensi energi air sebesar $3.102 \mathrm{MW}$ dimana potensi tersebut merupakan gabungan antara provinsi Jambi, Bengkulu, Lampung dan Sumatera Selatan dengan kapasitas terpasang saat ini sebesar 13,6 MW atau sebesar 0,438\% dari potensi yang ada. Kapasitas pembangkit pada provinsi Bengkulu berada dibawah dari RUEN di sepanjang 2015-2019. Kapasitas terpasang pembangkit sampai dengan tahun 2019 memiliki rata-rata besaran gap antara RUEN dan aktual sebesar $-98 \%$.

16) Provinsi Kalimantan Barat merupakan provinsi yang memiliki potensi energi air sebesar 4.737 MW dengan kapasitas terpasang saat ini sebesar 234,27 MW atau sebesar 4,94\% dari potensi yang ada. Kapasitas pembangkitan menunjukkan peningkatan sejak tahun 2018 dengan rata-rata besar gap antara RUEN dan aktual sebesar 4.215\%.

17) Kapasitas PLTA di Provinsi Kalimantan Utara berdasarkan data RUEN dan aktual, kondisi pada tahun 2015-2019 menunjukkan 0 MW.

18) Provinsi Sulawesi Tenggara merupakan provinsi yang memiliki potensi energi air sebesar 6.340 MW dimana potensi tersebut merupakan gabungan antara provinsi Sulawesi Selatan dan Sulawesi Tenggara dengan kapasitas terpasang saat ini sebesar 0,5 MW atau sebesar 0,008\% dari potensi yang ada. Kapasitas terpasang pembangkit sampai dengan tahun 2019 memiliki rata-rata besaran gap antara RUEN dan aktual sebesar $68 \%$ dimana tidak terdapat ketertinggalan penyediaan pembangkitan selama 2016-2019.

19) Provinsi Kalimantan Selatan merupakan provinsi yang memiliki potensi energi air sebesar 16.844 MW dimana potensi tersebut merupakan gabungan antara provinsi Kalimantan Selatan dan Kalimantan Tengah dengan kapasitas terpasang saat ini sebesar $30 \mathrm{MW}$ atau sebesar $0,178 \%$ dari potensi yang ada. Kapasitas terpasang pembangkit sampai dengan tahun 2019 memiliki rata-rata besaran gap antara RUEN dan aktual menunjukkan 0\% dimana ketersediaan pembangkit telah sesuai dengan yang direncanakan.

20) Provinsi Sulawesi Utara merupakan provinsi yang memiliki potensi energi air sebesar 3.967 MW dimana potensi tersebut merupakan gabungan antara provinsi Sulawesi Tengah dan Sulawesi Utara dengan kapasitas terpasang saat ini sebesar 5,25 MW atau sebesar 0,132\% dari potensi yang ada. PLTA pada Sulawesi Utara menunjukkan kondisi lebih tinggi dari RUEN yang direncakan pada tahun 2015-2017 yang kemudian mengalami penurunan pada tahun 2018 yang kemudian stabil hingga tahun 2019. Secara keseluruhan, gap pada Sulawesi Utara menunjukkan angka -30\% dimana gap terbesar terjadi pada tahun 2018-2019.

21) Provinsi Lampung merupakan provinsi yang memiliki potensi energi air sebesar $3.102 \mathrm{MW}$ dimana potensi tersebut merupakan gabungan antara provinsi Jambi, Bengkulu, Lampung dan Sumatera Selatan dengan kapasitas terpasang saat ini sebesar $56 \mathrm{MW}$ atau sebesar 1,81\% dari potensi yang ada. Kapasitas pembangkitan menunjukkan tren pembangkitan yang sesuai dengan RUEN yaitu sebesar 56 MW. Pada tahun 2015-2017 menunjukkan kondisi 0 MW baik pada RUEN maupun aktual. Gap antara RUEN dan aktual menunjukkan 0\% yang dapat diintepretasikan bahwa program yang berjalan telah sesuai dengan yang direncanakan. 
22) Kapasitas PLTA di Provinsi Riau berdasarkan data RUEN dan aktual, kondisi pada tahun 2015-2019 menunjukkan 0 MW.

23) Provinsi Nusa Tenggara Barat merupakan provinsi yang memiliki potensi energi air sebesar $624 \mathrm{MW}$ dimana potensi tersebut merupakan gabungan antara provinsi Bali dan Nusa Tenggara Timur dengan kapasitas terpasang saat ini sebesar 2,02 MW atau sebesar 0,324\% dari potensi yang ada. Kapasitas terpasang pembangkit sampai dengan tahun 2019 selalu berada lebih besar dari RUEN.

24) Kapasitas PLTA di Provinsi Maluku berdasarkan data RUEN dan aktual, kondisi pada tahun 2015-2019 menunjukkan 0 MW.

\section{Kesimpulan}

Secara keseluruhan kondisi pembangkitan PLTA berdasarkan pemodelan RUEN dan kondisi aktual menunjukkan progres yang baik, dimana gap antara RUEN dan aktual menunjukkan gap sebesar 3\% lebih besar dari RUEN atau sebesar 221,44 MW.

Overview lebih lanjut dilakukan pada masing-masing wilayah/provinsi dimana progres pelaksanaan program berdasarkan RUEN menunjukkan progres tinggi pada Provinsi Kalimantan Barat yakni sebesar 234,27 MW dari perencanaan 2,2 MW sedangkan Provinsi Aceh menunjukkan provinsi yang memiliki progres paling rendah jika dibandingkan dengan provinsi lain yakni sebesar 2,64 MW dari perencanaan 128,4 MW.

Studi lebih lanjut diperlukan untuk mengetahui kondisi atau perkembangan yang menyebabkan keterlambatan pada setiap provinsi sehingga dapat digunakan sebagai lesson learned bagi provinsi lain.

\section{Daftar Pustaka}

Astro, R. B., Doa, H., \& Hendro, H. (2020). Fisika Kontekstual Pembangkit Listrik Tenaga Mikrohidro. ORBITA: Jurnal Kajian, Inovasi Dan Aplikasi Pendidikan Fisika, 6(1), 142. https://doi.org/10.31764/orbita.v6i1.1858

Badan Pusat Statistik. (2020). Statistik Listrik 2014-2019. http://library1.nida.ac.th/termpaper6 /sd/2554/19755.pdf

Dalimi, R. (2018). Analisa Feed-in Tariff Energi Terbarukan Menggunakan Acuan Bpp Setempat Di Indonesia. 5-10.

Erinofiardi, Gokhale, P., Date, A., Akbarzadeh, A., Bismantolo, P., Suryono, A. F., Mainil, A. K., \& Nuramal, A. (2017). A Review on Micro Hydropower in Indonesia. Energy Procedia, 110(March), 316-321. https://doi.org/10.1016/j.egypro.2017.03.146

Fachri, A., Triastianti, R. D., \& Indrawati, R. (2019). Studi Potensi Debit dan Tinggi Jatuh Air pada Energi Listrik Kawasan Ekowisata di Desa Sriharjo, Teknik Energi, Institut Teknologi Yogyakarta. 19(1), 1-14.

Notosudjono, D., Suhendi, D., \& Wismiana, E. (2016). Permasalahan Dan Solusi Pengembangan Energi Terbarukan Di Indonesia. Proceedings Seminar Nasional Teknik Elektro (FORTEI 2016), 149152.

Ratnata, I. W., Surya S, W., \& Somantri, M. (2013). Analisis Potensi Pembangkit Energi Listrik Tenaga Air Di Saluran Air Sekitar Universitas Pendidikan Indonesia. FPTK Expo - UPI, November 2002, 254-261. 
Vol. 2, No. 3, pp $133-143$

doi: $10.14710 /$ jebt.2021.10045

Wahid, A. (2006). Perbandingan Biaya Pembangkitan Pembangkit Listrik di Indonesia. Pengembangan Sistem Kelistrikan Dalam Menunjang Pembangunan Nasional Jangka Panjang, 58-68.

Widyaningsih, G. A. (2017). Peraturan Presiden Nomor 22 Tahun 2017 tentang Rencana Umum Energi Nasional. Jurnal Hukum Lingkungan Indonesia, 4(1), 139. https://doi.org/10.38011/jhli.v4i1.53

Windarti, M. (2014). Potensi Debit Air Bendung Tegal untuk Pembangkit Listrik Tenaga Mikrohidro (PLTMH) dan Irigasi di Desa Kebonagung dan Desa Sriharjo Kecamatan Imogiri Kabupaten Bantul. 